\title{
ANALISIS KOMITMEN IBU BEKERJA DALAM MENYUSUI SAMPAI USIA 6 BULAN DI TEMPAT PENITIPANAN ANAK
}

\author{
Analysis Of Breastfeeding Commitments Up To 6 Months In Women Working \\ In Daycare
}

Indria Nuraini

Prodi D III Kebidanan, Fakultas Sains Kesehatan, Universitas PGRI Adi Buana Surabaya indria@unipasby.ac.id

\begin{abstract}
ABSTRAK
Latar Belakang : Ibu bekerja sering mengalami kegagalan dalam memberikan ASI Eksklusif. Penyebab kegagalan ASI Eksklusif dipengaruhi oleh banyak sebab, baik dari faktor internal maupun eksternal.

Tujuan : Penelitian ini bertujuan untuk mengetahui faktor-faktor yang mempengaruhi komitmen dalam memberikan ASI sampai usia 6 bulan.

Metode penelitian : jenis penelitian diskriptif observasional dengan pendekatan Cross Sectional, populasi ibu bekerja dengan usia anak 3-12 bulan, tehnik pengambilan sample random sampling 30. Uji analisa data dengan chie square dan uji regresi logistic berganda.

Hasil Penelitian : Penelitian ini menghasilkan hubungan yang signifikan umur $(\rho=0,013)$ dan paritas $(\rho=0,029)$ terhadap komitmen ibu dalam memberikan ASI, dengan kekuatan 134 kali umur 20-35 dan 5.000 kali paritas kurang dari 4 memberikan ASI sampai usia 6 bulan.

Kesimpulan : yang dapat diambil pada penelitian ini yaitu menyusui secara eksklusif dapat berhasil jika terdapat komitmen yang kuat pada ibu bekerja dalam menyusui.
\end{abstract}

Kata kunci: Ibu Bekerja, Komitmen, Menyusui sampai usia 6 bulan

\section{ABSTRACT}

Background : Working mothers often experience failure in providing exclusive breastfeeding. The causes of failure of exclusive breastfeeding are influenced by many reasons, both internal and external factors.

The Purpose : This study aims to determine the factors that influence commitment to breastfeeding until the age of 6 months.

Method: The research method is descriptive observational with a cross sectional approach, the population of working mothers with children aged 3-12 months, 30 random sampling technique. Test data analysis with chie square and multiple logistic regression test.

Result : This study resulted in a significant relationship between age $(\rho=0.013)$ and parity $(\rho=0.029)$ on mother's commitment to breastfeeding, with a strebgth of 134 times the age of 20-35 and 5,00 times the parity of less than four breastfeeding until the age of 6 months. 
Conclusion : The conclusion that can be drawn in this study is that exclusive breastfeeding can be successful if there is a strong commitment to working mothers in breastfeeding

Keywords:Mother works; Commitment; word 3; Breastfeed until 6 months of age

\section{PENDAHULUAN}

ASI merupakan makanan terbaik bagi bayi, karena banyak mengandung nutrisi penting untuk pertumbuhan dan perkembangan. Salah satu manfaat ASI yaitu meningkatkan kecerdasan anak dengan mempertimbangkan kandungan ASI, cara pemberian serta lama waktu pemberian ASI. Pada hasil penelitian, kandungan ASI seperti Taurin, DHA, dan AA (Arachidonic Acid) sangat stabil jika dibandingkan susu formula, sehingga sangat bermanfaaat untuk pembentukan sel-sel otak serta mempercepat stimulus ke otak (Hanafi, 2015).

Hasil suatu penelitian, anak yang diberikan ASI memiliki Intelectual Quotient 7-8 tingkat dibandingkan yang tidak memberikan ASI. Dan ketika dewasa akan menurunkan resiko terjadinya hipertensi, kolesterol, over weight, obesitas serta diabetes tipe 2(Yuliarti, 2010)

Menurut Riskesdas tahun 2018, di Indonesia proporsi bayi mendapatkan ASI sampai usia 5 bulan yaitu 37,3\%, ASI parsial 9,3\% dan ASI Predominan $3,3 \%$, sedangkan jawa timur ASI usia 0-5 bulan $40 \%$, ASI parsial $10 \%$ dan $2 \%$ ASI predominan, kondisi ini masih cukup jauh dari target yang ditentukan oleh pemerintah yaitu capaian ASI Eksklusif 80\% (Riskesdas 2018, 2018). Ada beberapa faktor yang mempengaruhi keberhasilan pemberian ASI eksklusif, yaitu kemampuan melakukan pemberian ASI segera (Immediate breastfeeding), dilakukannya rooming-in, penundaan pemberian makanan atau minuman tambahan dan komitmen yang kuat dari ibu atapun bidan untuk memberikan ASI eksklusif(Fikawati \& Syafiq, 2010).

Penelitian yang di lakukan di Lebanon didapatkan bahwa bayi diperkenalkan makanan padat pada usia $>4$ bulan dengan ibu yang bekerja di luar rumah (Batal et al., 2010). Faktor penyebab tidak berhasilnya ASI Eksklusif pada ibu bekerja yaitu berkurangnya produksi ASI, diakibatkan oleh beban atau tuntutan pekerjaan, fasilitas menyusui yang kurang mendukung di tempat kerja, dukungan teman kerja serta jarak rumah dengan tempat kerja. Akibat dari faktorfaktor tersebut menyebabkan berkurangnya komitmen ibu untuk memberikan ASI secara Eksklusif.

Suatu penelitian dengan responden ibu hamil yang dilakukan di Amerika, Afrika dan Aukasia dengan judul Confident Commitment Is a Key Factor for Sustained Breastfeeding, menyatakan bahwa keberhasilan menyusui ditentukan oleh Confident Commitment (komitmen kepercayaan diri), berisi tentang keyakinan dalam proses menyusui, percaya diri dengan kemampuan dalam menyusui dan komitmen keberhasilan menyusui meskipun ada kendala. Sehingga dapat disimpulkan bahwa menyusui merupakan keterampilan yang dapat 
dipelajari dan keberhasilan dalam menyusui sangat bergantung pada komitmen kepercayaan diri pada ibu(Avery et al., 2009)

Tujuan penelitian ini adalah menganalisis faktor-faktor yang mempengaruhi komitmen ibu bekerja dalam memberikan ASI sampai usia 6 bulan.

\section{METODE}

Desain penelitian ini Diskriptif Observasional dengan pendekatan Cross Sectional dengan populasi ibu-ibu yang usia anak 3-12 bulan dan menitipkan di daycare (Tempat Penitipan Anak). Tehnik pengambilan sampel dengan Random Sampling dan berjumlah 30 responden. Teknik pengumpulan data dilakukan dengan menyebarkan kuesioner pada responden kemudian dilakukan editing, coding, tabulating dan di analisis dengan Chie Square dan uji regresi logistic berganda.

\section{HASIL DAN PEMBAHASAN}

\section{Hasil}

Penelitian Analisis Komitmen Ibu Bekerja dalam Menyusui sampai Usia 6 bulan didapatkan hasil sebagai berikut:

Tabel 1. Distribusi Frekuensi Karakteristik Responden

\begin{tabular}{lcc}
\hline \multicolumn{1}{c}{ Karakterstik } & Frekuensi (f) & Prosentase (\%) \\
\hline Umur & & \\
20-35 tahun & 19 & 63,3 \\
$\geq 35$ tahun & 11 & 36,7 \\
Paritas & & \\
Anak $<4$ & 16 & 53,3 \\
Anak $\geq 4$ & 14 & 46,7 \\
Pendidikan & & 13,3 \\
Non PT & 4 & 86,7 \\
PT & 26 & 63,3 \\
Pekerjaan & & 36,7 \\
Non PNS & 19 & 26,7 \\
PNS & 11 & 73,3 \\
Peran Pengasuh & & \\
Tidak mendukung & 8 & \\
Mendukung & 22 & \\
\hline
\end{tabular}

Sumber data primer, tahun 2017

Pada tabel diatas Prosentase responden terbesar dengan umur $<20-35$ tahun $(63,3 \%)$, paritas anak <4 $(53,3 \%)$, pendidikan PT atau lulusan Perguruan Tinggi $(86,7 \%)$, pekerjaan Non PNS $(63,3 \%)$ serta Peran pengasuh mendukung pemberian ASI (73,3\%). 
Tabel 2. Analisis faktor yang mempengaruhi komitmen dalam menyusui sampai Usia 6 bulan

\begin{tabular}{|c|c|c|c|c|}
\hline \multirow[t]{2}{*}{ Variabel } & \multicolumn{2}{|c|}{ Komitmen Menyusui } & \multirow[t]{2}{*}{$\rho($ Value $)$} & \multirow[t]{2}{*}{ OR } \\
\hline & $<6$ bulan & $\geq 6$ bulan & & \\
\hline Umur & & & 0,013 & 134 \\
\hline 20-35 tahun & 5 & 14 & & \\
\hline$\geq 35$ tahun & 8 & 3 & & \\
\hline Paritas & & & 0,029 & 5.778 \\
\hline$<4$ & 13 & 6 & & \\
\hline$\geq 4$ & 3 & 8 & & \\
\hline Pendidikan & & & 0,102 & - \\
\hline Non PT & 4 & 15 & & \\
\hline PT & & 11 & & \\
\hline Pekerjaan & & & 0,481 & - \\
\hline Non PNS & 11 & 8 & & \\
\hline PNS & 8 & 3 & & \\
\hline Peran Pengasuh & & & 0,098 & 5.833 \\
\hline Tidak mendukung & 7 & 1 & & \\
\hline Mendukung & 12 & 10 & & \\
\hline
\end{tabular}

Hasil analisis uji chie square dan regresi logistic berganda yaitu terdapat hubungan yang signifikan pada umur $(\rho=0,013)$ dan paritas $(\rho=0,029)$ terhadap komitmen ibu menyusui. Usia ibu antara 20-35 tahun memiliki pengaruh $134 \mathrm{kali}$ dalam memberikan ASI sampai usia lebih dari 6 bulan, sedang ibu dengan jumlah anak $<4$ berkomitmen 5.000 kali dalam memberikan ASI Eksklusif.

\section{Pembahasan}

Pada tabel 1. Sebagian besar dengan pendidikan perguruan tinggi dengan pekerjaan non PNS (Karyawan Swasta). Lama pemberian ASI pada ibu bekerja ditentukan oleh beberapa faktor, seperti pendidikan ibu, pengetahuan, komitmen, status social ekonomi, tempat melahirkan serta dukungan suami(Kusumajaya et al., 2009). Perilaku seseorang ditentukan oleh pengetahuan (Notoadmodjo, 2007), sehingga dapat disimpulkan jika seseorang mempunyai pengetahuan yang baik tentang ASI dan menyusui maka kemungkinan besar akan memberikan ASI secara Eksklusif.

Tingkat usia responden antara 20-35 tahun dengan memberikan ASI sampai usia 6 bulan. Berdasarkan hasil penelitian Rahmawati dan Prayogi, usia 20-35 tahun merupakan usia yang matang dalam reproduksi dan psikologi, sehingga ibu lebih tenang dan siap dalam proses menyusui dan secara tidak langsung akan memperlancar produksi ASI. Sedangkan pada usia > 35 tahun terjadi penurun fungsi reproduksi, salah satunya fungsi hormone menyusui tetapi matang dalam psikologi terutama pengalaman menyusui yang baik(Rahmawati \& Prayogi, 2017). Paritas sejalan dengan hasil penelitian yang menyatakan bahwa ibu dengan jumlah anak lebih dari tiga cenderung tidak memberikan ASI Eksklusif sedang ibu yang jumlah anaknya kurang tiga lebih banyak memberikan ASI Eksklusif (Amaliah \& Siti Arifah Pujonarti, 2013). Ada dua faktor predisposisi yang sangat 
berpengaruh terhadap praktek pemberian ASI sampai 6 bulan yaitu umur dan paritas. Ibu yang cukup umur dan memiliki anak lebih banyak memiliki kemungkinan besar untuk memberikan ASI Eksklusif meskipun dengan tingkat pengetahuan yang sama(Fikawati \& Syafiq, 2010)

Pada peran pengasuh terhadap Komitmen tidak terdapat hubungan yang signifikan $(\rho=0,098)$ tetapi 5.000 kali mendukung komitmen ibu dalam memberikan ASI sampai usia enam bulan. Pengasuh ini dapat diartikan orang yang berperan dalam merawat bayinya ketika ditinggal bekerja bisa nenek/asisten rumah tangga/tempat penitipan anak/TPA. Hal ini sejalan dengan hasil penelitian yang memaparkan bahwa faktor pendorong ibu bekerja dalam memberikan ASI Eksklusif dan berkelanjutan adalah pengetahuan dan sikap pemilik TPA (fasilitas ramah ASI), bimbingan dan pembinaan TPA, tetapi semua keputusan pemberian ASI terletak pada komitmen ibu menyusui (Wulansari, 2016). Perilaku dan praktek pemberian ASI dapat dipengaruhi oleh lingkungan social seperti suami, nenek, teman dekat dan penyelia kesehatan. Dukungan dapat berupa perhatian,rasa hormat, nasihat, dorongan dan bantuan(Meedya et al., 2010)

\section{SIMPULAN DAN SARAN}

\section{Simpulan}

Komitmen ibu dalam menyusui adalah sangat penting agar tercapai ASI Eksklusif, dengan tidak memandang usia, paritas, pendidikan, dan pekerjaan. Peran lingkungan sosial sangat penting dalam menunjang keberhasilan menyusui baik dari orang terdekat (suami atau keluarga) serta pengasuh bayi dalam keberlanjutan menyusui. Sehingga dari penelitian ini dapat disimpulkan bahwa usia dan paritas sangat mempengaruhi komitmen ibu dalam menyusui sampai usia 6 bulan.

\section{Saran}

Tenaga kesehatan (bidan, dokter, ataupun tenaga kesehatan yang lain) untuk terus memberikan pendidikan kesehatan mengenai pentingnya ASI dan menyusui kepada ibu, suami, keluarga ataupun orang-orang terdekat baik dalam lingkungan keluarga ataupun tempat kerja. Selain itu untuk tempat kerja harus menerapkan ramah ASI, dengan menyediakan fasilitas menyusui.

\section{DAFTAR PUSTAKA}

Amaliah, N., \& Siti Arifah Pujonarti. (2013). HUBUNGAN STATUS GIZI DENGAN STATUS MENARCHEPADA REMAJA (USIA 10-15 TAHUN) DI INDONESIA TAHUN 2010. Jurnal Kesehatan Reproduksi, 4, No 2, 6171 (2013).

Avery, A., Zimmermann, K., Underwood, P. W., \& Magnus, J. H. (2009). Confident commitment is a key factor for sustained breastfeeding. Birth, 36(2), 141-148. https://doi.org/10.1111/j.1523-536X.2009.00312.x

Batal, M., Boulghourjian, C., \& Akik, C. (2010). Complementary feeding patterns 
in a developing country: a cross-sectional study across Lebanon. Health Journal, Vol.16 No.2. Hal. 180-186 (2010)

Fikawati, S., \& Syafiq, A. (2010). Penyebab Keberhasilan dan Kegagalan Praktik Pemberian ASI Eksklusif. Kesehatan Masyarakat Nasional, 16424, 1-2. https://doi.org/10.21109/kesmas.v4i3.184

Hanafi, Y. (2015). Peningkatan Kecerdasan Anak Melalui Pemberian ASI dalam al-Qur'an. Mutawatir, Vo.2, No.1, Hal : 27-45 (2012) https://doi.org/10.15642/mutawatir.2012.2.1.27-45

Kusumajaya, A. A. N., Widarti, I. G. A. A., \& Ariati, N. N. (2009). PENINGKATAN PENGETAHUAN DAN KOMITMEN IBU HAMIL UNTUK MENYUSUI DALAM UPAYA PENCAPAIAN KEBERHASILAN PEMBERIAN ASI EKSKLUSIF A.A. Ngurah Kusumajaya 1 , I G.A. Ari Widarti 2 , N.N. Ariati 3. 11-17.

Meedya, S., Fahy, K., \& Kable, A. (2010). Factors that positively influence breastfeeding duration to 6 months: A literature review. Women and Birth, Vol.23, No.4, Hal. 135-145. https://doi.org/10.1016/j.wombi.2010.02.002

Notoadmodjo, S. (2007). Pendidikan dan Perilaku Manusia (2nd ed.). Rineka Cipta.

Rahmawati, A., \& Prayogi, B. (2017). Analisis Faktor Yang Mempengaruhi Produksi Air Susu Ibu (ASI) Pada Ibu Menyusui Yang Bekerja. Jurnal Ners Dan Kebidanan, Vol. 4, No.2, Hal. 134-140. https://doi.org/10.26699/jnk.v4i2.ART.p134-140

Riskesdas 2018. (2018). HASIL UTAMA RISKESDAS 2018 Kesehatan. 20-21. http://www.depkes.go.id/resources/download/infoterkini/materi_rakorpop_2 018/Hasil Riskesdas 2018.pdf

Wulansari, W. E. (2016). DALAM MENDUKUNG PEMBERIAN ASI ESKLUSIF DAN KELANJUTAN PEMBERIAN ASI Studi Kualitatif di Kota Semarang THE ROLE OF CHILD NURSERY IN SUPPORTING EXCLUSIVE Februari. http://eprints.undip.ac.id/67096/

Yuliarti, N. (2010). Keajaiban ASI-Makanan terbaik untuk Kesehatan, Kecerdasan, dan Kelincahan si kecil. Penerbit Andi. https://books.google.co.id/books?hl=id\&lr=\&id=q92ckECrZekC\&oi=fnd\&p $\mathrm{g}=\mathrm{PR} 3 \& \mathrm{dq}=$ pengaruh $+\mathrm{ASI}+$ terhadap+kecerdasan+anak\&ots=b0eHsc6bf $1 \& \mathrm{~s}$ ig=FXJ0AcZ2Z5oleVnXNkRVZibplpw\&redir_esc=y\#v=onepage \&q=pengar uh ASI terhadap kecerdasan anak\&f=false 